\title{
Author Correction: The demise of the largest and oldest African baobabs
}

Adrian Patrut (D), Stephan Woodborne (D), Roxana T. Patrut, Laszlo Rakosy, Daniel A. Lowy, Grant Hall and Karl F. von Reden (1)

Correction to: Nature Plants https://doi.org/10.1038/s41477-018-0170-5, published online 11 June 2018.

In Supplementary Table 1 originally published with this Brief Communication, the authors gave an incorrect GPS easterly coordinate for tree number 12 (Makulu Makete Big baobab); the coordinate ' $22^{\circ} 34.584^{\prime}$ S, $25^{\circ} 52.261^{\prime}$ E' should have read ' $22^{\circ} 34.584^{\prime}$ S, $28^{\circ} 52.261^{\prime}$ E. This has now been amended in the online Supplementary Information file for this Brief Communication. 